OPEN ACCESS

Edited by:

Sarah K. Tasian,

University of Pennsylvania, USA

Reviewed by:

Leonardo R. Brandao,

The Hospital for Sick Children,

Canada

Peter Michael Gordon,

University of Minnesota, USA

${ }^{*}$ Correspondence:

Arash Mahajerin

amahajerin@choc.org

Specialty section: This article was submitted to Pediatric Hematology and Hematological Malignancies,

a section of the journal

Frontiers in Pediatrics

Received: 23 November 2016 Accepted: 20 March 2017 Published: 10 April 2017

Citation:

Mahajerin A and Croteau SE (2017) Epidemiology and

Risk Assessment of Pediatric Venous Thromboembolism.

Front. Pediatr. 5:68.

doi: 10.3389/fped.2017.00068

\section{Epidemiology and Risk Assessment of Pediatric Venous Thromboembolism}

\author{
Arash Mahajerin $^{1 *}$ and Stacy E. Croteau ${ }^{2}$ \\ ${ }^{1}$ CHOC Children's Specialists, Orange, FL, USA, ${ }^{2}$ Boston Children's Hospital, Boston, MA, USA
}

The incidence of diagnosed venous thromboembolism (VTE) has been increasing concurrent with advances in technology and medical care that enhance our ability to treat pediatric patients with critical illness or complex multiorgan system dysfunction. Although the overall incidence of VTE is estimated at 0.07-0.49 per 10,000 children, higher rates are observed in specific populations including hospitalized children, those with central venous catheters (CVCs) or patients convalescing from a major surgery. While the absolute number of pediatric VTE events may seem trivial compared to adults, the increasing incidence, associated with increased mortality and morbidity, the availability of novel therapies, and the impact on the cost of care have made investigation of VTE risk factors and prevention strategies a high priority. Many putative risk factors for pediatric VTE have been reported, primarily from single-institution, retrospective studies which lack appropriate methods for verifying independent risk factors. In addition, some risk factors have inconsistent definitions, which vex meta-analyses. CVCs are the most prevalent risk factors but have not consistently been assigned the highest level of risk as defined by odds ratios from retrospective, case-control studies. Few risk-assessment models for hospital-acquired pediatric VTE have been published. Some models focus exclusively on hospitalized pediatric patients, while others target specific populations such as patients with cancer or severe trauma. Multicenter, prospective studies are needed to identify and confirm risk factors in order to create a pediatric risk-assessment tool and optimize preventive measures and reduce unintended harm.

Keywords: epidemiology, pediatrics, thrombosis, risk factors, risk assessment

\section{INTRODUCTION}

Understanding and intervening on preventable factors that provoke venous thromboembolism (VTE) in pediatrics is a leading initiative for children's hospitals (1). As the second leading cause of hospital-acquired morbidity (preventable harm) for children in the U.S., VTE significantly increases hospitalization costs. Using the nationwide inpatient sample, one recent analysis estimated increased mean hospital costs of $\$ 27,686$ and mean length of stay (LOS) extension of 8.1 days in children with hospital-acquired VTE (HA-VTE) compared to controls (2).

The foundation of our current knowledge of pediatric VTE has emerged primarily through registries, administrative databases, and retrospective cohort studies (3-8). Differences in the patient population included and analysis make comparison of these studies challenging. The relative 
contributions of genetic, anatomic, and acquired risk factors in pediatrics have been less studied than in adults $(9,10)$. Sequelae of VTE, namely post-thrombotic syndrome (PTS) and recurrence risk, have not been fully investigated in children, but efforts to standardize outcome measures are underway (11-13). This pediatric VTE compendium contains mini-reviews on VTE in the setting of cancer, congenital heart disease, inflammatory states, central venous catheters (CVCs), trauma, and thrombophilia. This mini-review will focus on epidemiology of pediatric VTE as well as patient and acquired risks. For additional discussion of pediatric VTE in a specific disease or clinical state, see the accompanying mini-reviews.

\section{INCIDENCE}

The estimated incidence of pediatric VTE in developed countries ranges from 0.07 to 0.49 per 10,000 children $(3,14)$. VTE rates are notably higher in hospitalized children, $4.9-21.9$ per 10,000 hospital admissions $(3,14,15)$. A bimodal distribution is evident. The most prominent peak is in early infancy accounting for up to $20 \%$ of pediatric VTE. A second peak occurs during adolescence with about $50 \%$ of VTE events occurring in children 11-18 years old. Reported incidence rates vary due to differences in study design, cohort inclusion criteria (e.g., all events versus symptomatic events, whether neonates are included, and/or if age-specific sub-analyses are performed), whether the source of information is a database based on billing codes or whether radiological confirmation was required for inclusion. For example, VTE incidence rates in the Netherlands decreased from 0.14 per 10,000 children to 0.05 per 10,000 children when neonates and non-extremity VTE events were excluded (8).

While the annual burden of thrombosis is greater in adults (5.6-16 per 10,000 adults per year) $(9,16)$, the rate of increase in observed incidence in children discharged from tertiary care hospitals is notable. Cohort studies targeting HA-VTE demonstrate a steep rise in incidence, increasing from 0.3 to 28.8 cases per 10,000 admissions (1992-2005) in one study and from 34 to 58 cases per 10,000 admissions (2001-2007) in another $(17,18)$. In contrast to the majority of studies focused on hospital-based populations, longitudinal data from a population-based cohort study in Québec, QC, Canada found a stable VTE incidence of 0.29 events per 10,000 person-years in children less than 18 years old over the 11-year study period ending in 2004 (5). Notably, this study excluded patients less than 1 year of age, and rates were calculated based on person-years, as opposed to VTE rate per hospital admissions.

The majority of VTE diagnosed in children arise proximal to hospitalization and are considered provoked. At least one risk factor is identified in the majority of patients (19-21). This stands in contrast to adults where $30-50 \%$ of VTE events are idiopathic or spontaneous. CVC-associated VTE predominates in pediatrics. In the absence of a CVC, however, location frequency of VTE varies by age group. Renal vein VTE comprises a significant proportion of events in neonates but is exceedingly rare in older children where lower extremity VTE is more likely. Although rare, non-extremity VTE in children may arise in portal, splenic, mesenteric, pulmonary vessels, or cerebral sinuses (22). No racial or ethnic variations have been described, and data on gender differences are conflicting.

Pediatric subpopulations have higher VTE incidence including children with critical illness, neoplasm, renal disease (nephrotic syndrome), congenital heart disease, inflammatory bowel disease, or obesity and neonates. Children admitted to the intensive care unit (ICU) have a $2 \%$ higher risk of VTE if they had a short-term CVC and LOS greater than 7 days (23). Occurrence of VTE in neonates has been estimated as high as 24 per 10,000 neonatal intensive care admissions (20). There are presently no standard thromboprophylaxis guidelines to mitigate increased VTE risk.

\section{RISK FACTORS}

Many patient attributes, medical diagnoses, and elements of hospitalized care have been shown or suggested to confer HA-VTE risk. Risk factor data are predominately derived from single-institution, retrospective cohort, or case-control studies (10).

\section{Immobility}

Absence of consensus on terms altered mobility versus immobility creates a challenge when attempting to define the associated risk of these states and potential risk reduction with intervention. Data from adults show a strong association with various etiologies of immobility, e.g., post-surgery, plaster cast. Altered mobility without immobilization also increases risk of symptomatic DVT but to a lesser extent than chronic immobilization $(24,25)$. Wells' criteria for suspected DVT have "recently bedridden for 3 days or more" in their clinical model (26). The benchmark of 3 days or more has previously been suggested to confer a high degree of risk in pediatrics but has not been prospectively studied (27). Multiple studies have implicated altered mobility as a risk factor for pediatric HA-VTE. Unfortunately, the granularity to understand and compare duration or degree of altered mobility among studies is lacking (10).

The Braden Q mobility assessment offers a guide for grading mobility (28); however, HA-VTE risk has not been clinically correlated to a threshold score. Prospective evaluation of mobility rubrics in both children and adults is needed to determine VTE risk associated with different mobility states.

\section{Infection}

Infection is often cited as a risk factor without descriptors of location, extent, severity, or inciting organism $(29,30)$. Occasionally, a specified set of infectious conditions (e.g., meningitis, bacteremia) are categorized as "infection" (31), or infection is dichotomized to focal or systemic. Systemic infections are thought to confer higher risk than a focal infection, but this may depend on location. For example, otitis media or mastoiditis are considered "focal" infections and associated with increased risk of cerebral sinus venous thrombosis (32). Similarly, acute osteomyelitis has been noted to increase risk of VTE in adjacent veins (33). Evaluation of different infectious events and reporting confirmation, e.g., culture, is needed to understand VTE risk of focal and systemic infections. Concomitant inflammation likely 
plays a role but may prove difficult to identify independent risk separate from the infection.

\section{Intensive Care Unit}

Recent work has evaluated whether admission to or prolonged stay in the ICU is a risk factor for HA-VTE. One study demonstrated ICU admission confers independent VTE risk in all pediatric patients (27). Two studies in pediatric trauma have demonstrated independent VTE risk with ICU admission and ICU stay $\geq 4$ days $(34,35)$. It is likely that ICU admission or prolonged stay is a proxy for illness severity and need for additional interventions, e.g., CVCs, mechanical ventilation that directly contributes to increased VTE risk.

\section{Length of Stay}

While recent data have highlighted extended LOS following HA-VTE, the mechanism by which prolonged hospitalization increases risk is less clear (2). Compounding the challenge are differences in analysis. LOS is a continuous variable but has been analyzed as both a continuous and a dichotomous variable. In two independent retrospective, case-control studies, Branchford et al. and Sharathkumar et al. utilized greater than 5 and 7 days, respectively, as cutoff values for increased VTE risk based on the distribution around the day of hospitalization on which VTE occurred $(27,36)$. Branchford et al. reported the odds of HA-VTE increasing by $3 \%$ for each additional day beyond 5 days. Pediatric trauma-specific literature has demonstrated daily increases in HA-VTE risk of 2 and 3\% for those admitted with traumatic brain injury and general trauma, respectively $(37,38)$. Future research detailing increases in daily risk in the context of concomitant risk factors and whether risk can also decrease with elimination of other risk factors is lacking but would prove beneficial in understanding how LOS impacts VTE risk.

\section{Mechanical Ventilation}

Mechanical ventilation is emerging as a risk factor, but the magnitude of independent risk is unclear. Similar to ICU admission, mechanical ventilation may be a proxy for a severely ill child. In both trauma and critical care pediatric populations, mechanical ventilation has been identified as an independent VTE risk factor (36-38). One study observed an increased risk with $\geq 4$ days of mechanical ventilation (35). Determining how independent risk for VTE increases with each additional day of mechanical ventilation, outside of the trauma setting requires investigation.

\section{Obesity}

Being overweight and obese in pediatrics is defined as body mass indices of 85 th -94 th and $\geq 95$ th percentiles, respectively (39). Obesity increases VTE risk through a chronic low-grade inflammatory state, platelet activation, and endothelial dysfunction (40). VTE risk due to obesity has been well-characterized in adults (41). Minimal pediatric-specific data exist. A retrospective, case-control study of 48 children with VTE identified increased risk in obese children but not overweight children. This study was confounded by frequent co-occurrence of known risk factors in obese children and a small sample size (42).

\section{Oral Contraceptive Pills}

Venous thromboembolism risk with combined oral contraceptive pills (COCPs) has been studied extensively. Estrogen has a multitude of mechanisms that increase thrombotic risk including increases in pro-coagulant proteins, decreases in counterregulatory proteins including protein $S$ and antithrombin, and inducing protein $\mathrm{C}$ resistance (43). While differences exist between route of delivery, type of progesterone, and the doses of estrogen and progesterone, the highest level of risk is thought to occur in the first 3 months of use and gradually plateaus after 12 months of use (44). The overall relative risk is threefold to fivefold higher than non-users of COCPs. Risk increases significantly with concomitant inherited thrombophilia (45). Studies examining VTE risk of progesterone-only contraception are conflicting. Some studies have shown increased risk, particularly with depot medroxyprogesterone and high-dose oral progesterone, whereas other studies have observed no increase in baseline risk, primarily with low-dose oral progesterone and progesterone-only intra-uterine implantable devices (44).

\section{Surgery}

Similar to infection, analyzing surgery is problematic given broad use of the term. Surgery is often reported as a risk factor without defining risk related to a specific procedure or its duration (15, 46). Procedures may be divided into major or minor, but these are neither consistently nor uniformly defined. For example, Van Arendonk et al. defined major surgery as involving the nervous, respiratory, cardiovascular, digestive, urinary, or musculoskeletal systems or spleen (38). Furthermore, not all studies defined the time interval between surgery and VTE. Previous work has defined VTE risk as 7 and 15 days prior to VTE diagnosis (46, 47). The duration of surgery has yet to be explored in pediatrics, but adult data have shown increasing VTE risk with increasing surgery duration (48).

\section{RISK-ASSESSMENT MODELS}

Several risk-assessment models have been published for pediatric HA-VTE (Table 1) (23, 36, 49-52). Branchford et al. showed independent risk with mechanical ventilation, systemic infection, and hospital stay $\geq 5$ days, and that these three factors co-occurring yielded a posttest probability of $3.1 \%$ for HA-VTE (36). Sharathkumar et al. derived six independent risk factors and assigned points from beta coefficients in the logistic regression model: immobilization (3), LOS $\geq 7$ days (2), OCPs (2), CVC (1), bacteremia (1), and direct ICU admission (0.5). A cumulative score of $\geq 3$ yielded a positive predictive value of $2.45 \%$ for HA-VTE at a prevalence of $0.71 \%(27)$.

Two separate risk-assessment models, one for critically ill children and another for non-critically ill children, were created from a single institution during the same time period by retrospective, case-control study designs $(23,49)$. In non-critically ill children, scores of 8,7 , and $\leq 6$ correlated to risk of HA-VTE of 12.5, 1.1, and $0.1 \%$, respectively (49). In critically ill children, scores of 15 , $7-14$, and $\leq 6$ correlated to risk of HA-VTE of $8.8,1.3$, and $0.03 \%$, respectively (23). 
TABLE 1 | Pediatric venous thromboembolism risk-assessment models.

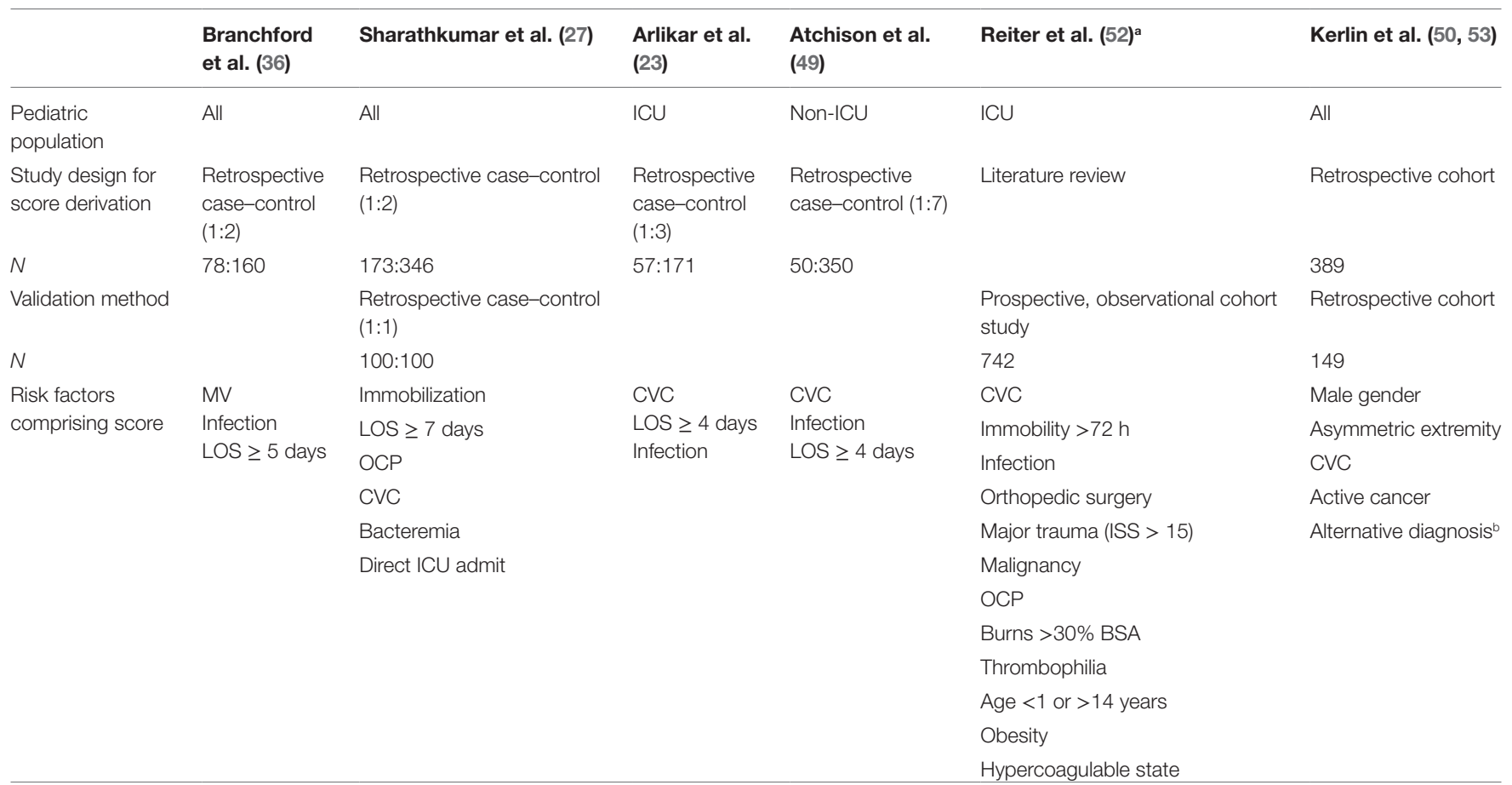

ICU, intensive care unit; MV, mechanical ventilation; LOS, length of stay; OCP, oral contraceptive pill; CVC, central venous catheters; ISS, injury severity score; BSA, body surface area.

ancluded venous and arterial thromboembolism in their study.

${ }^{b}$ Presence of this factor results in point reduction from score.

Kerlin et al. derived an equation that uses 0 or 1 for absence or presence of certain factors (53):

VET probability $=\left\{\mathrm{e}^{\wedge}[1.086\right.$ (male) +0.595 (asymmetric extremity) $+0.643(\mathrm{CVC})+0.549$ (active cancer) -1.11 (alternative diagnosis) $-2.03]\} /\left\{1+\mathrm{e}^{\wedge}[1.086\right.$ (male) +0.595 (asymmetric extremity) +0.643 $(\mathrm{CVC})+0.549$ (active cancer) -1.11 (alternative diagnosis $)-2.03]\}$

Reiter et al. created an ICU-specific risk-assessment model (excluded cardiac ICU) for "pre-hospital" and "in-hospital" thromboses but included both venous and arterial events (52). They derived 12 risk factors from existing literature and weighted them equally with 1 point. They found for every 1 point increase in total score, the risk of a symptomatic thrombosis increased by 1.57 -fold ( $95 \%$ confidence interval $0.132-5.49$ ) to 2.12 -fold (95\% confidence interval $0.175-18.34$ ) for "pre-hospital" and "in-hospital" thrombi, respectively $(p<0.05)$ (52).

The model by Prentiss describes levels of risk, Risk Score 1-3, but neither details which risk factors comprise the scoring system nor their individual point values (51). Additional models have been derived for children with acute lymphoblastic leukemia (54), pediatric oncology patients with a CVC-related VTE (55), and pediatric trauma (56).

To date, a multi-institutional risk-assessment model has been lacking in the literature, but current research is underway to address this gap (57). The Children's Hospital-Acquired Thrombosis (CHAT) Registry is a multi-institution registry with three planned phases of research. The first phase is a retrospectively derived risk-assessment model based on logistic regression. There are seven institutions contributing cases and controls (1:2), and as of January 1, 2017, there are 647 unique subjects with VTE in the registry (enrollment ongoing). Once the risk-assessment model is developed, it will be prospectively validated it in a separate multiinstitutional study, i.e., phase 2 . If validated, a randomized controlled trial investigating the utility of the CHAT risk-assessment model will be designed and conducted as the third phase.

\section{MORBIDITY}

Acute VTE sequelae depend on location and severity. Pulmonary thromboses may lead to pulmonary hypertension or cardiovascular instability. Thrombosis of the superior vena cava (SVC) or thoracic vessels may result in SVC syndrome. Extremity DVTs induce pain and swelling. VTE in patients with renal disease has been associated with 2 -fold increase in hospital admissions and 10-fold increase in LOS (53). Neonates have increased risk of chronic renal insufficiency following renal vein thrombosis.

Risk of VTE recurrence has been variably reported but is estimated around $10 \%$ in children and $3 \%$ in neonates $(9,18)$. Comorbidities such as cardiovascular disease, malignancy, and neurovascular disorders have been associated with increased likelihood of recurrence. Patients with identified thrombophilia variants, e.g., prothrombin gene mutation and antithrombin deficiency, may also be at increased risk of recurrent VTE. PTS, chronic venous insufficiency associated extremity pain, edema, 
and stasis dermatitis, appear less frequent and severe in children (12.4\%) compared to adults (30\%); however, this likely represents underreporting as outcomes studies are limited and most have relatively short durations of follow-up (58). PTS occurs most commonly in the lower extremities. Recently, the Scientific and Standardization Committee of the International Society on Thrombosis and Haemostasis recommended use of a pediatric modification of the Villalta score for adult PTS to standardize reporting in children (11).

\section{MORTALITY}

Venous thromboembolism in children is associated with increased mortality. VTE mortality rates of 11.4 per 1,000 child-years have been reported, greater than age-specific mortality estimated at 6.4 per 1,000 child-years in a population-based study conducted in Canada (5). This finding is consistent with data from several registries that report all-cause mortality in those with VTE of $9-17 \%$. In one study, over $20 \%$ of deaths were noted to occur within 30 days of VTE diagnosis (8). The highest mortality rate is in the youngest patients. Fortunately, mortality rates directly attributed to VTE are low, 1.5-2.2\%. Risk of fatality associated with pulmonary embolism is less in pediatrics compared to adults (59).

\section{CONCLUSION}

Pediatric VTE is increasing in incidence. Key contrasting points between adults and children are that pediatric VTE is more likely

\section{REFERENCES}

1. SPS. Children's Hospital's Solutions for Patient Safety. (2016). Available from: http://www.solutionsforpatientsafety.org/about-us/how-it-all-started/

2. Goudie A, Dynan L, Brady PW, Fieldston E, Brilli RJ, Walsh KE. Costs of venous thromboembolism, catheter-associated urinary tract infection, and pressure ulcer. Pediatrics (2015) 136(3):432-9. doi:10.1542/peds. 2015-1386

3. Andrew M, David M, Adams M, Ali K, Anderson R, Barnard D, et al. Venous thromboembolic complications (VTE) in children: first analyses of the Canadian Registry of VTE. Blood (1994) 83(5):1251-7.

4. Massicotte MP, Dix D, Monagle P, Adams M, Andrew M. Central venous catheter related thrombosis in children: analysis of the Canadian registry of venous thromboembolic complications. J Pediatr (1998) 133(6):770-6. doi:10.1016/ S0022-3476(98)70149-0

5. Sabapathy CA, Djouonang TN, Kahn SR, Platt RW, Tagalakis V. Incidence trends and mortality from childhood venous thromboembolism: a population-based cohort study. J Pediatr (2016) 172:175-80.e171. doi:10.1016/j. jpeds.2016.02.017

6. Tormene D, Simioni P, Prandoni P, Franz F, Zerbinati P, Tognin G, et al. The incidence of venous thromboembolism in thrombophilic children: a prospective cohort study. Blood (2002) 100(7):2403-5. doi:10.1182/blood-200204-1186

7. Tuckuviene R, Christensen AL, Helgestad J, Johnsen SP, Kristensen SR. Pediatric venous and arterial noncerebral thromboembolism in Denmark: a nationwide population-based study. J Pediatr (2011) 159(4):663-9. doi:10.1016/j.jpeds.2011.03.052

8. van Ommen $\mathrm{CH}$, Heijboer $\mathrm{H}$, Buller $\mathrm{HR}$, Hirasing RA, Heijmans HS, Peters M. Venous thromboembolism in childhood: a prospective two-year registry in The Netherlands. J Pediatr (2001) 139(5):676-81. doi:10.1067/ mpd.2001.118192 to be diagnosed in a hospital and have recognizable antecedent provocation. As incidence increases, associated morbidities, mortality, and health-care costs do likewise. Clearer understanding of pediatric-specific risk factors and validated risk-assessment models are needed to reduce preventable harm and investigate the efficacy of targeted prophylaxis interventions. A multitude of risk factors have been identified for pediatric VTE, but many need further elucidation. Similarly, risk-assessment models to date provide an initial approach but ultimately lack prospective validation and correlation to outcomes. The multi-institution CHAT registry is poised to overcome these limitations and provide details regarding the magnitude of risk attributable to patient, disease, and interventional factors. Initial results are anticipated in 2017. If successful, the CHAT Registry may serve as the foundation of a risk-stratified, randomized controlled trial to evaluate thromboprophylaxis measures in pediatrics.

\section{AUTHOR CONTRIBUTIONS}

$\mathrm{AM}$ and SC cowrote the manuscript, and each revised and edited the entire manuscript.

\section{FUNDING}

AM received a 2016 Mentored Research Award from the Hemostasis and Thrombosis Research Society (HTRS), which was supported by Baxalta US Inc. SC is the recipient of a 20142016 National Hemophilia Foundation (NHF) Baxter Clinical Fellowship, supported by Baxalta.

9. Spentzouris G, Scriven RJ, Lee TK, Labropoulos N. Pediatric venous thromboembolism in relation to adults. J Vasc Surg (2012) 55(6):1785-93. doi:10.1016/j.jvs.2011.07.047

10. Mahajerin A, Branchford BR, Amankwah EK, Raffini L, Chalmers E, van Ommen $\mathrm{CH}$, et al. Hospital-associated venous thromboembolism in pediatrics: a systematic review and meta-analysis of risk factors and risk-assessment models. Haematologica (2015) 100(8):1045-50. doi:10.3324/ haematol.2015.123455

11. Goldenberg NA, Brandão L, Journeycake J, Kahn SR, Monagle P, Revel-Vilk $S$, et al. Definition of post-thrombotic syndrome following lower extremity deep venous thrombosis and standardization of outcome measurement in pediatric clinical investigations. J Thromb Haemost (2012) 10(3):477-80. doi:10.1111/j.1538-7836.2011.04594.x

12. Rajpurkar M, Sharathkumar A, Williams S, Lau K, Ling SC, Chan AKC. Recommendations for the assessment of non-extremity venous thromboembolism outcomes: communication from the SSC of the ISTH. J Thromb Haemost (2015) 13(3):477-80. doi:10.1111/jth.12809

13. Revel-Vilk S, Brandao LR, Journeycake J, Goldenberg NA, Monagle P, Sharathkumar A. et al. Standardization of post-thrombotic syndrome definition and outcome assessment following upper venous system thrombosis in pediatric practice. J Thromb Haemost (2012) 10(10):2182-5. doi:10.1111/j.1538-7836.2012.04885.x

14. Stein PD, Kayali F, Olson RE. Incidence of venous thromboembolism in infants and children: data from the National Hospital Discharge Survey. J Pediatr (2004) 145(4):563-5. doi:10.1016/j.jpeds.2004.06.021

15. Kim SJ, Sabharwal S. Risk factors for venous thromboembolism in hospitalized children and adolescents: a systemic review and pooled analysis. J Pediatr Orthop B (2014) 23(4):389-93. doi:10.1097/BPB.0000000000000053

16. Meissner MH, Wakefield TW, Ascher E, Caprini JA, Comerota AJ, Eklof B, et al. Acute venous disease: venous thrombosis and venous trauma. J Vasc Surg (2007) 46(Suppl S):25S-53S. doi:10.1016/j.jvs.2007.08.037 
17. Sandoval JA, Sheehan MP, Stonerock CE, Shafique S, Rescorla FJ, Dalsing MC. Incidence, risk factors, and treatment patterns for deep venous thrombosis in hospitalized children: an increasing population at risk. J Vasc Surg (2008) 47(4):837-43. doi:10.1016/j.jvs.2007.11.054

18. Raffini L, Huang YS, Witmer C, Feudtner C. Dramatic increase in venous thromboembolism in children's hospitals in the United States from 2001 to 2007. Pediatrics (2009) 124(4):1001-8. doi:10.1542/peds.2009-0768

19. Chalmers EA. Epidemiology of venous thromboembolism in neonates and children. Thromb Res (2006) 118(1):3-12. doi:10.1016/j.thromres.2005. 01.010

20. Young G, Albisetti M, Bonduel M, Brandao L, Chan A, Friedrichs F, et al. Impact of inherited thrombophilia on venous thromboembolism in children: a systematic review and meta-analysis of observational studies. Circulation (2008) 118(13):1373-82. doi:10.1161/CIRCULATIONAHA.108. 789008

21. Klaassen IL, van Ommen CH, Middeldorp S. Manifestations and clinical impact of pediatric inherited thrombophilia. Blood (2015) 125(7):1073-7. doi:10.1182/blood-2014-05-536060

22. Pergantou H, Avgeri M, Komitopoulou A, Xafaki P, Kapsimali Z, Mazarakis $\mathrm{M}$, et al. Venous thromboembolism at uncommon sites in neonates and children. JPediatr Hematol Oncol (2014) 36(8):624-9. doi:10.1097/ MPH.0000000000000116

23. Arlikar SJ, Atchison CM, Amankwah EK, Ayala IA, Barrett LA, Branchford BR, et al. Development of a new risk score for hospital-associated venous thromboembolism in critically-ill children not undergoing cardiothoracic surgery. Thromb Res (2015) 136(4):717-22. doi:10.1016/j.thromres.2015. 04.036

24. Engbers MJ, Blom JW, Cushman M, Rosendaal FR, van Hylckama Vlieg A. The contribution of immobility risk factors to the incidence of venous thrombosis in an older population. J Thromb Haemost (2014) 12(3):290-6. doi:10.1111/ jth. 12480

25. Haas S, Spyropoulos AC. Primary prevention of venous thromboembolism in long-term care: identifying and managing the risk. Clin Appl Thromb Hemost (2008) 14(2):149-58. doi:10.1177/1076029607311779

26. Wells PS, Anderson DR, Rodger M, Forgie M, Kearon C, Dreyer J, et al. Evaluation of D-dimer in the diagnosis of suspected deep-vein thrombosis. $N$ Engl J Med (2003) 349(13):1227-35. doi:10.1056/NEJMoa023153

27. Sharathkumar AA, Mahajerin A, Heidt L, Doerfer K, Heiny M, Vik T, et al. Risk-prediction tool for identifying hospitalized children with a predisposition for development of venous thromboembolism: Peds-Clot Clinical Decision Rule. J Thromb Haemost (2012) 10(7):1326-34. doi:10.1111/j.15387836.2012.04779.x

28. Quigley SM, Curley MA. Skin integrity in the pediatric population: preventing and managing pressure ulcers. J Soc Pediatr Nurs (1996) 1(1):7-18. doi:10.1111/ j.1744-6155.1996.tb00050.x

29. Pai N, Ghosh K, Shetty S. Acquired and heritable thrombophilia in Indian patients with pediatric deep venous thrombosis (DVT). Clin Appl Thromb Hemost (2014) 20(6):573-6. doi:10.1177/1076029613476339

30. Pillai P, Bonny AE, O'Brien SH. Contraception-related venous thromboembolism in a pediatric institution. J Pediatr Adolesc Gynecol (2013) 26(3):186-8. doi:10.1016/j.jpag.2013.02.009

31. Wright JM, Watts RG. Venous thromboembolism in pediatric patients: epidemiologic data from a pediatric tertiary care center in Alabama. J Pediatr Hematol Oncol (2011) 33(4):261-4. doi:10.1097/MPH.0b013e3182 134111

32. Barnes C, Newall F, Furmedge J, Mackay M, Monagle P. Cerebral sinus venous thrombosis in children. J Paediatr Child Health (2004) 40(1-2):53-5. doi:10.1111/j.1440-1754.2004.00291.x

33. Crary SE, Buchanan GR, Drake CE, Journeycake JM. Venous thrombosis and thromboembolism in children with osteomyelitis. JPediatr (2006) 149(4):537-41. doi:10.1016/j.jpeds.2006.06.067

34. Askegard-Giesmann JR, O'Brien SH, Wang W, Kenney BD. Increased use of enoxaparin in pediatric trauma patients. J Pediatr Surg (2012) 47(5):980-3. doi:10.1016/j.jpedsurg.2012.01.060

35. O'Brien SH, Candrilli SD. In the absence of a central venous catheter, risk of venous thromboembolism is low in critically injured children, adolescents, and young adults: evidence from the National Trauma Data Bank. Pediatr Crit Care Med (2011) 12(3):251-6. doi:10.1097/PCC.0b013e3181f36bd9
36. Branchford BR, Mourani P, Bajaj L, Manco-Johnson M, Wang M, Goldenberg NA. Risk factors for in-hospital venous thromboembolism in children: a case-control study employing diagnostic validation. Haematologica (2012) 97(4):509-15. doi:10.3324/haematol.2011.054775

37. Harris DA, Lam S. Venous thromboembolism in the setting of pediatric traumatic brain injury. J Neurosurg Pediatr (2014) 13(4):448-55. doi:10.3171/2014.1.PEDS13479

38. Van Arendonk KJ, Schneider EB, Haider AH, Colombani PM, Stewart FD, Haut ER. Venous thromboembolism after trauma: when do children become adults? JAMA Surg (2013) 148(12):1123-30. doi:10.1001/jamasurg. 2013.3558

39. Spear BA, Barlow SE, Ervin C, Ludwig DS, Saelens BE, Schetzina KE, et al. Recommendations for treatment of child and adolescent overweight and obesity. Pediatrics (2007) 120(Suppl 4):S254-88. doi:10.1542/peds.20072329F

40. Darvall KA, Sam RC, Silverman SH, Bradbury AW, Adam DJ. Obesity and thrombosis. Eur J Vasc Endovasc Surg (2007) 33(2):223-33. doi:10.1016/j. ejvs.2006.10.006

41. Holst AG, Jensen G, Prescott E. Risk factors for venous thromboembolism: results from the Copenhagen City Heart Study. Circulation (2010) 121(17):1896-903. doi:10.1161/CIRCULATIONAHA.109.921460

42. Stokes S, Breheny P, Radulescu A, Radulescu VC. Impact of obesity on the risk of venous thromboembolism in an inpatient pediatric population. Pediatr Hematol Oncol (2014) 31(5):475-80. doi:10.3109/08880018.2014. 886315

43. Tchaikovski SN, Rosing J. Mechanisms of estrogen-induced venous thromboembolism. Thromb Res (2010) 126(1):5-11. doi:10.1016/j.thromres.2010. 01.045

44. Rott H. Thrombotic risks of oral contraceptives. Curr Opin Obstet Gynecol (2012) 24(4):235-40. doi:10.1097/GCO.0b013e328355871d

45. Trenor CC III, Chung RJ, Michelson AD, Neufeld EJ, Gordon CM, Laufer MR, et al. Hormonal contraception and thrombotic risk: a multidisciplinary approach. Pediatrics (2011) 127(2):347-57. doi:10.1542/peds.2010-2221

46. Sirachainan N, Chuansumrit A, Angchaisuksiri P, Pakakasama S, Hongeng S, Kadegasem P. Venous thromboembolism in Thai children. Pediatr Hematol Oncol (2007) 24(4):245-56. doi:10.1080/08880010701360767

47. van Ommen $\mathrm{CH}$, Heijboer H, van den Dool EJ, Hutten BA, Peters M. Pediatric venous thromboembolic disease in one single center: congenital prothrombotic disorders and the clinical outcome. J Thromb Haemost (2003) 1(12):2516-22. doi:10.1046/j.1538-7836.2003.00465.x

48. Kim JYS, Khavanin N, Rambachan A, McCarthy RJ, Mlodinow AS, De Oliveria GS Jr, et al. Surgical duration and risk of venous thromboembolism. JAMA Surg (2015) 150(2):110-7. doi:10.1001/jamasurg.2014.1841

49. Atchison CM, Arlikar S, Amankwah E, Ayala I, Barrett L, Branchford BR, et al. Development of a new risk score for hospital-associated venous thromboembolism in noncritically ill children: findings from a large single-institutional case-control study. J Pediatr (2014) 165(4):793-8. doi:10.1016/j. jpeds.2014.05.053

50. Kerlin BA, Stephens JA, Hogan MJ, Smoyer WE, O’Brien SH. Development of a pediatric-specific clinical probability tool for diagnosis of venous thromboembolism: a feasibility study. Pediatr Res (2015) 77(3):463-71. doi:10.1038/ pr.2014.198

51. Prentiss AS. Early recognition of pediatric venous thromboembolism: a risk-assessment tool. Am J Crit Care (2012) 21(3):178-183; quiz 184. doi:10.4037/ajcc2012548

52. Reiter PD, Wathen B, Valuck RJ, Dobyns EL. Thrombosis risk factor assessment and implications for prevention in critically ill children. Pediatr Crit Care Med (2012) 13(4):381-6. doi:10.1097/PCC.0b013e31823893f5

53. Kerlin BA, Smoyer WE, Tsai J, Boulet SL. Healthcare burden of venous thromboembolism in childhood chronic renal diseases. Pediatr Nephrol (2015) 30(5):829-37. doi:10.1007/s00467-014-3008-z

54. Mitchell L, Lambers M, Flege S, Kenet G, Li-Thiao-Te V, Holzhauer S, et al. Validation of a predictive model for identifying an increased risk for thromboembolism in children with acute lymphoblastic leukemia: results of a multicenter cohort study. Blood (2010) 115(24):4999-5004. doi:10.1182/ blood-2010-01-263012

55. Revel-Vilk S, Yacobovich J, Tamary H, Goldstein G, Nemet S, Weintraub $\mathrm{M}$, et al. Risk factors for central venous catheter thrombotic complications 
in children and adolescents with cancer. Cancer (2010) 116(17):4197-205. doi:10.1002/cncr.25199

56. Connelly CR, Laird A, Barton JS, Fischer PE, Krishnaswami S, Schreiber $\mathrm{MA}$, et al. A clinical tool for the prediction of venous thromboembolism in pediatric trauma patients. JAMA Surg (2016) 151(1):50-7. doi:10.1001/ jamasurg.2015.2670

57. Mahajerin ABB, Jaffray J, Vasquez B, Stillings A, Smith N, Goldenberg N, et al. Children's Hospital-Acquired Thrombosis Database (CHAT): a multiinstitutional database for prospective identification of independent risk factors [abstract \#1111]. In: 57th Annual American Society of Hematology Meeting and Exposition. Orlando, FL (2015).

58. Monagle P, Adams M, Mahoney M, Ali K, Barnard D, Bernstein M, et al. Outcome of pediatric thromboembolic disease: a report from the Canadian Childhood Thrombophilia Registry. Pediatr Res (2000) 47(6):763-6. doi:10.1203/00006450-200006000-00013
59. Victoria T, Mong A, Altes T, Jawad AF, Hernandez A, Gonzalez L, et al. Evaluation of pulmonary embolism in a pediatric population with high clinical suspicion. Pediatr Radiol (2009) 39(1):35-41. doi:10.1007/s00247-008$1037-0$

Conflict of Interest Statement: The authors declare that the research was conducted in the absence of any commercial or financial relationships that could be construed as a potential conflict of interest.

Copyright $\odot 2017$ Mahajerin and Croteau. This is an open-access article distributed under the terms of the Creative Commons Attribution License (CC BY). The use, distribution or reproduction in other forums is permitted, provided the original author(s) or licensor are credited and that the original publication in this journal is cited, in accordance with accepted academic practice. No use, distribution or reproduction is permitted which does not comply with these terms. 